\title{
Optimizing the dosing and trickling of nutrient media for thermophilic biomethanation in a biotrickling filter
}

\author{
Muhammad Tahir Ashraf ${ }^{1^{*}}$, Lars Yde ${ }^{1}$, Jin Mi Triolo ${ }^{1}$, and Henrik Wenzel ${ }^{1}$ \\ ${ }^{1}$ Department of Green Technology, University of Southern Denmark, Odense DK-5230, Denmark \\ *corresponding author: muta@igt.sdu.dk
}

June 16, 2021

\begin{abstract}
Ex-situ biomethanation in a biotrickling filter is being developed as a robust technology for the conversion of $\mathrm{CO}_{2}$ to $\mathrm{CH}_{4}$ using $\mathrm{H}_{2}$ generated from renewable power. The technology uses hydrogenotrophic methanogens in a biofilm as the catalyst and the optimum supply of nutrients in the biofilm is imperative for stable and long-term operation. In this study, essential nutrients for the methanogens in the biotrickling filter were highlighted along with a systemic investigation of the nutrient supply methods. The results showed that ammonium and iron were the critical nutrients with a minimum required concentration of $0.3 \mathrm{~g} / \mathrm{L}$ and 1.5 $\mathrm{mg} / \mathrm{L}$, respectively. Furthermore, thoroughly wetting the biofilm with nutrient media, either using flooding or trickling at a high-rate, was needed to maintain an active biofilm; although, these methods temporarily reduce the conversion for a duration of 18 to $24 \mathrm{~h}$ due to the formation of the thicker water film.
\end{abstract}

Keywords: biomethanation, biogas, hydrogenotrophic methanogens, nutrients, power-to-methane 


\section{Introduction}

Power-to-methane (PtM) is a potential solution for the storage of excess renewable power [1] and it is a source of low carbon gaseous fuel [2]. The interest in PtM is supported by the fact that the product, methane $\left(\mathrm{CH}_{4}\right)$, can be utilized in the existing natural gas infrastructure. For example, the EU has a network of approx. 2 million $\mathrm{km}$ of transmission and distribution with 800 TWh of underground storage for natural gas [2]. PtM can be applied for the conversion of industrial and/or biogenic $\mathrm{CO}_{2}$ to $\mathrm{CH}_{4}$. Overall, application of PtM can integrate the renewable power grid with biomethane/nautral gas grid, which will offer flexibility to the electricity grid while aiding decarbonization of other sectors [3]. It is estimated that by 2050 about $150 \mathrm{TWh}$ (14 bcm natural gas equivalent) of PtM could be produced in the EU using biogenic $\mathrm{CO}_{2}$ captured from biogas plants combined with locally produced $\mathrm{H}_{2}$ using electricity from solar and wind power [4]. The application of PtM at a biogas plant is also a substitute for the conventional biogas upgrading process, where $\mathrm{CO}_{2}$ is removed from the biogas to increase its heating value. Whereas, using $\mathrm{PtM}$ the $\mathrm{CO}_{2}$ is utilized to produce $\mathrm{CH}_{4}$ that increases the heating value and the overall $\mathrm{CH}_{4}$ output from biogas plant.

Several studies have shown the ex-situ biomethanation using biotrickling filter (BTF) as a feasible technology for PtM and for the biogas upgrading [5-8]. The BTF is a 3 phase reactor where the HM are grown over a packing material as biofilm, the gaseous substrates $\left(\mathrm{H}_{2}\right.$ and $\left.\mathrm{CO}_{2}\right)$ pass over the biofilm, and the liquid nutrient media is trickled over the packed bed to supply the nutrients. The solubility of $\mathrm{H}_{2}$ is approx. 40 times lower than $\mathrm{CO}_{2}$ and the overall process is mass transfer limited [9]. The arrangement of HM over a packing material offers a relatively large surface area for the mass transfer of gaseous substrates that results in higher mass transfer rates. The main advantage of BTF is the relatively higher volumetric rate of $\mathrm{CH}_{4}$ production as compared to the other biomethanation technologies. For example, $\mathrm{CH}_{4}$ production rate of $15.4 \mathrm{Nm}^{3} / \mathrm{m}^{3} \mathrm{~d}$ was achieved using a lab scale BTF [10] as compared to $3.7 \mathrm{Nm}^{3} / \mathrm{m}^{3} \mathrm{~d}$ using CSTR [11] and $0.25 \mathrm{Nm}^{3} / \mathrm{m}^{3} \mathrm{~d}$ using upflow reactor [12]. In addition, the BTF does not require stirring or gas recirculation and hences offers a lower operating cost. The BTF technology can also be applied with other sources of $\mathrm{CO}_{2}$, e.g. for biomethanation of syngas [13].

In BTF the conversion of $\mathrm{CO}_{2}$ and $\mathrm{H}_{2}$ to $\mathrm{CH}_{4}$ is carried out by the hydrogenotrophic methanogens (HM), a class of anaerobic archaea found in the anaerobic digester for the biogas production. The HM are enriched and immobilized on a packing material in the form of biofilm and the substrate gases pass over it. The optimal supply of the nutrients is essential for the continuous operation of BTF because 
the methanogens are dependent on their availability. Major elements found in the methanogenic microorganism are $\mathrm{C}, \mathrm{H}, \mathrm{N}, \mathrm{Na}, \mathrm{K}, \mathrm{S}, \mathrm{P}, \mathrm{Ca}$, and trace elements are $\mathrm{Fe}, \mathrm{Ni}, \mathrm{Co}, \mathrm{Mn}, \mathrm{Zn}, \mathrm{Cu}$, and Mo [14]. Central to the hydrogenotrophic methanogenesis pathway are enzyme complexes that catalyze redox reactions, and these enzymes contain transition metals as cofactors for electron transport or as catalytic centers at active sites. Important transition metals for methanogenic archaea are $\mathrm{Fe}, \mathrm{Ni}$, $\mathrm{Co}, \mathrm{Mn}$, and $\mathrm{Zn}$ and low bioavailability of transition metals limits the methanogenesis in pure and mixed cultures $[15,16]$. The depletion of trace metals results in process imbalances because they are essential in enzyme complexes [17]. Specifically, for the hydrogenotrophic methanogenesis, the hydrogenases are Ni-Fe enzymes that oxidize $\mathrm{H}_{2}$ and reduce ferredoxin (coenzyme $\mathrm{F}_{420}$ ) [18]. These energy converting hydrogenases are abundant in $\mathrm{Fe}$ and contain a cluster of $\mathrm{Fe}_{4} \mathrm{~S}_{4}$ with a Ni-Fe active site. For example, the membrane-associated hydrogenases contain three $\mathrm{Fe}_{4} \mathrm{~S}_{4}$ clusters and a Ni-Fe active site [14], and can contain additional polyferredoxin subunits with 6, 10, or $14 \mathrm{Fe}_{4} \mathrm{~S}_{4}$ clusters and a Ni-Fe active site [19]. Another type of hydrogenase contains four $\mathrm{Fe}_{4} \mathrm{~S}_{4}$ clusters and a $\mathrm{Ni}-\mathrm{Fe}$ active site [20]. Physiological studies of pure cultures have shown that optimal metal concentrations for microbial metabolism are orders of magnitude higher than in situ concentrations [16]. In the case of biofilm reactors, such as BTF, the nutrient concentration required could be higher due to the diffusion resistance in the water and biofilm. In addition, for the biofilm reactors the supply method of the nutrients over the packing materials plays a vital role.

The availability of nutrients is needed for the stability of anaerobic digester for biogas production which is operated with energy crops, animal excreta, crop residues, organic fraction of municipal solid wastes or any other type of organic waste [21], and have been studied in detail [22, 23]. As compared to the anaerobic digestion, the substrate for the ex-situ biomethanation in BTF is simple, i.e. $\mathrm{H}_{2}$ and $\mathrm{CO}_{2}$, hence nutrients supplementation is more essential. However, to the best of our knowledge, analytical investigation of nutrient consumption and the analysis of nutrient dosing and supply methods have not been carried out for BTF, specifically for the long-term continuous operation of the reactor. In this study, an optimization of the nutrients dosing and supply method was studied for stable operation of ex-situ biomethanation in a BTF. Essential nutrients were identified along with their minimum concentration levels, followed by a systematic approach to find the effective method of supplying these nutrients. The dosing method relates to the frequency of supplementation of the nutrients in the nutrient media sump and the supply method relates to the method of trickling the nutrient media over the biofilm in the BTF. After the optimization of the nutrient dosing and supply methods, the maximization of methane production was investigated. 


\section{Materials and Methods}

\subsection{Experimental setup}

The schematic layout of the BTF reactor and the connections to ancillary equipment are shown in Figure 1. The reactor body was built using a clear polyvinyl chloride pipe. The inner diameter was 5.4 $\mathrm{cm}$, packed length was $22 \mathrm{~cm}$, working volume $\left(V_{r}\right)$ was $503.8 \mathrm{~mL}$, and media sump volume $\left(V_{s}\right)$ was $400 \mathrm{~mL}$. The reactor had a heating jacket that was made by wrapping a silicon tube $(6.4 \mathrm{~mm}$ inner diameter) around the whole length of the reactor. On top of the heating jacket, a layer of thermal foam insulation was wrapped. Water at $57^{\circ} \mathrm{C}$ was circulated from a water bath in the silicon tube to maintain thermophilic conditions in the reactor. The reactor was packed with finned Raschig rings made of polyethylene and had the size of $7 \mathrm{~mm}$ x $10 \mathrm{~mm}$ (PE08, Tongxiang Small Boss Special Plastic Products Ltd. (http://www.smallboss.com/). One piece of the packing materials had a vendor quoted surface area of $3500 \mathrm{~m}^{2} / \mathrm{m}^{3}$. The bed void fraction of the packing material was measured to be $76 \%$.

The feed gas used was a mix of $\mathrm{N}_{2}, \mathrm{CO}_{2}$, and $\mathrm{H}_{2}$. The inlet flowrate of these gas components was controlled using thermal conductivity-based mass flow controllers (EL-FLOW Select series, Bronkhorst ${ }^{\circledR}$ ).

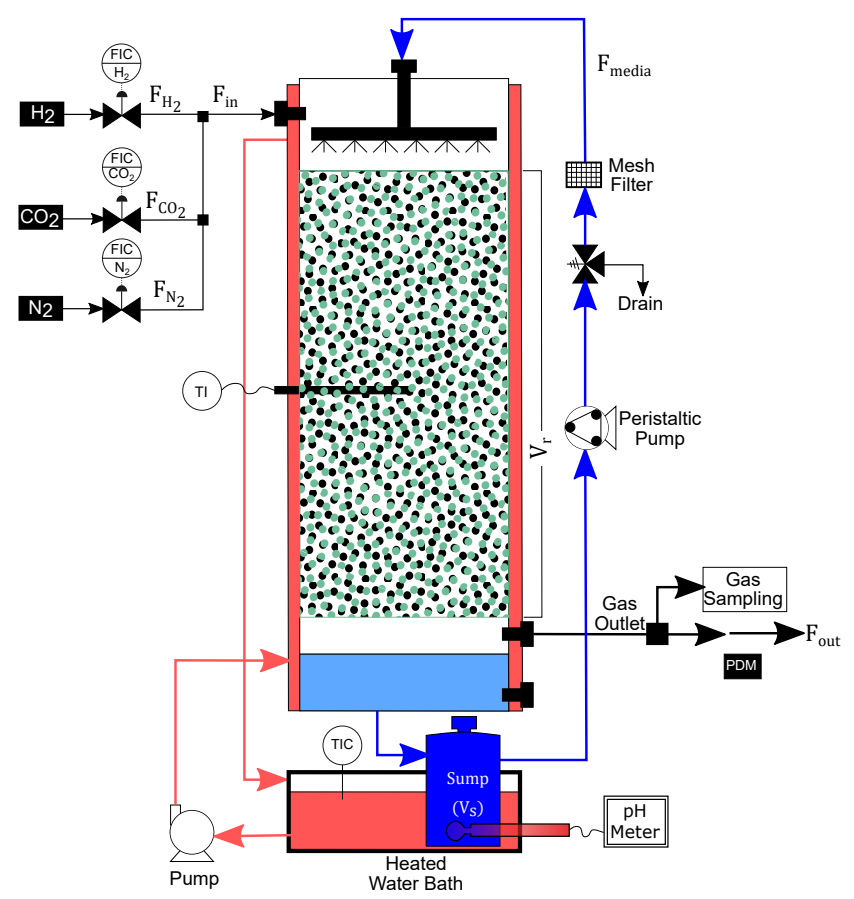

Figure 1: Schematic diagram of biotrickling filter reactor. FIC-flow indicator controller, TIC-temperature indicator controller, TI-temperature indicator, PDM-positive displacement meter. 
Nutrient media was trickled from the sump to the top of the reactor using a peristaltic pump (Watson Marlow Qdos30 Universal Pump). A 125-micron mesh filter was installed in the media line connecting the peristaltic pump and the reactor. The filter stops the larger particle size solids from entering the reactor, which was the modification made after the clogging of the BTF reactor in an earlier study [24]. The filter was cleaned regularly. A relief valve with a set point of 100 mbar was installed before the filter. The relief valve provided safety in case the peristaltic pump was running, and the filter got clogged. The $\mathrm{pH}$ in the nutrient media sump was measured using a digital $\mathrm{pH}$ meter with the probe (INTELLICAL PHC735, HACH Lange) mounted in the sump. The outlet flowrate of the gas was measured using a positive displacement type gas flowmeter ( $\mathrm{BPC}^{\circledR} \mu \mathrm{Flow}, \mathrm{BPC}$ Instruments $\mathrm{AB}$, Sweden).

\subsection{Nutrient media}

Pasteurized cow manure (PCM) was used as the nutrient media. The use of PCM has been validated as an effective nutrient media in the earlier study [8], however, the presence of solids in PCM led to eventual clogging of the BTF, as reported in [24]. In this study, an improved method of pretreating the manure was adopted that consisted of the following steps: (i) coarse sieving the cow manure to remove large solids and fibers, (ii) filtering through $500 \mu \mathrm{m}$ sieve, (iii) centrifugation at $8000 \mathrm{rpm}$ for $10 \mathrm{~min}$, (iv) filtering the supernatant through $125 \mu \mathrm{m}$ sieve, (v) and lastly heating the filtrate from 125 $\mu \mathrm{m}$ sieve till $70{ }^{\circ} \mathrm{C}$ for $1 \mathrm{hr}$. Two different batches of PCM were prepared and their analysis is given in Table 1. PCM Batch 1 was used from the start of reactor operation till day 280 and PCM Batch 2 was used afterward till day 450 .

\subsection{Inoculation}

The reactor was started using the direct inoculation methods as was reported in the earlier study [25]. Mixed anaerobic culture was used as inoculum that was obtained from the primary digester of Nature Energy Midtfyn biogas plant, Denmark. The inoculum was coarsely sieved to remove large solids and straw, afterwards, it was filtered through $125 \mu \mathrm{m}$ sieve. The filtered inoculum was degassed for one week at $55^{\circ} \mathrm{C}$ in an incubator. The analysis of the filtered and degassed inoculum is given in Table 1.

\subsection{Analytical methods}

Gas samples were collected in triplicates at the gas outlet of the reactor in $5.9 \mathrm{ml}$ vacuum vials (Exetainer ${ }^{\circledR}$ Evacuated Flat Bottom Vial). The composition of $\mathrm{H}_{2}, \mathrm{CO}_{2}, \mathrm{~N}_{2}$, and $\mathrm{CH}_{4}$ was analyzed using gas chromatography (GC, 7890A, Agilent Technologies, Santa Clara, CA, USA) equipped with a thermal conductivity detector and a fused silica capillary column (Carboxen ${ }^{\circledR} 1010$ PLOT, $30 \mathrm{~m} \times 0.53 \mathrm{~mm}$ ). The 
Table 1: Composition of the pasteurized cow manure (PCM) and inoculum.

\begin{tabular}{lccc}
\hline Parameter & PCM Batch 1 & PCM Batch 2 & Inoculum \\
\hline Total solids (TS, g/100g) & $2.27 \pm 0.01$ & $3.08 \pm 0.01$ & $4.18 \pm 0.14$ \\
Volatile solids (g/100g-TS) & $72.7 \pm 0.30$ & $68.7 \pm 0.58$ & $27.4 \pm 0.01$ \\
$\mathrm{pH}$ & 7.80 & 7.86 & 7.75 \\
Volatile fatty acids $(V F A)$ & & & \\
$\quad$ Acetate $(\mathrm{g} / \mathrm{L})$ & $1.04 \pm 0.17$ & $3.32 \pm 0.30$ & $0.77 \pm 0.002$ \\
$\quad$ Propionate $(\mathrm{g} / \mathrm{L})$ & $0.44 \pm 0.03$ & $1.59 \pm 0.0$ & $0.42 \pm 0.00$ \\
$\quad$ Butyrate $(\mathrm{g} / \mathrm{L})$ & $0.83 \pm 0.05$ & $0.28 \pm 0.01$ & $0.37 \pm 0.003$ \\
$\quad$ Valerate $(\mathrm{g} / \mathrm{L})$ & $0.76 \pm 0.02$ & $0.41 \pm 0.02$ & $0.39 \pm 0.003$ \\
Nutrients & & & \\
Ammonium $\left(\mathrm{NH}_{4}{ }^{+}, \mathrm{mg} / \mathrm{L}\right)$ & $1,771.1 \pm 5.3$ & $3,638.6 \pm 69.9$ & $3,091.0 \pm 15.8$ \\
Total nitrogen $(\mathrm{TN}, \mathrm{mg} / \mathrm{L})$ & $2,923.2 \pm 8.2$ & $\mathrm{~N} / \mathrm{A}$ & $4,436.9 \pm 8.2$ \\
Phosphate $\left(\mathrm{PO}{ }^{3-}{ }^{-}, \mathrm{mg} / \mathrm{L}\right)$ & $3,425.4 \pm 476.8$ & $1,547.8 \pm 300.9$ & $5,344.4 \pm 266.6$ \\
Potassium $\left(\mathrm{K}^{+}, \mathrm{mg} / \mathrm{L}\right)$ & $2,137.3 \pm 307.6$ & $3,888.6 \pm 209.1$ & $2,288.8 \pm 80.9$ \\
$\mathrm{Fe}(\mu \mathrm{g} / \mathrm{L})$ & $3,741.6 \pm 11.1$ & $13,082.4 \pm 334.7$ & $5,415.7 \pm 828.9$ \\
Co $(\mu \mathrm{g} / \mathrm{L})$ & $210.4 \pm 26.0$ & $\mathrm{~N} / \mathrm{A}$ & $84.5 \pm 11.9$ \\
$\mathrm{Ni}(\mu \mathrm{g} / \mathrm{L})$ & $104.8 \pm 3.1$ & $247.1 \pm 38.0$ & $126.9 \pm 5.1$ \\
$\mathrm{Mn}(\mu \mathrm{g} / \mathrm{L})$ & $628.8 \pm 4.7$ & $665.7 \pm 295.4$ & $606.3 \pm 16.3$ \\
\hline
\end{tabular}

temperature of the oven holding the column was maintained at $35^{\circ} \mathrm{C}$ with a holding time of 4 min, followed by a ramp of $25^{\circ} \mathrm{C} / \mathrm{min}$ up to $225^{\circ} \mathrm{C}$, and then maintained with a holding time of $2 \mathrm{~min}$. Ar was used as the carrier gas and certified gas mix standards from Mikrolab Aarhus A/S were used for the calibration of GC.

Liquid samples were collected from the nutrient media sump for the volatile fatty acids (VFA) and nutrient analysis. The nutrient analysis included $\mathrm{NH}_{4}{ }^{+}$, total nitrogen $(\mathrm{TN}), \mathrm{PO}_{4}{ }^{3-}, \mathrm{K}^{+}$, and trace metals Fe, Ni, Co, and Mn. The VFA concentration was measured using GC (7890B, Agilent Technologies, Santa Clara, CA, USA) equipped with a flame ionization detector (FID) and a polyethylene glycol column (HP-INNOWax, Agilent Technologies, Santa Clara, CA, USA; $30 \mathrm{~m} \times 0.25 \mathrm{~mm} \times 0.25$ $\mu \mathrm{m})$. Samples for the VFA analysis were pretreated before the analysis, where $0.10 \mathrm{~mL}$ of phosphoric acid ( $85 \mathrm{wt} \%$ ) and $0.5 \mathrm{ml}$ of DI water were added with $0.5 \mathrm{~mL}$ of the sample. After that, the samples were centrifuged for $15 \mathrm{~min}$ (Eppendorf mini Spin), filtered through a $0.5 \mu \mathrm{m}$ cellulose filter into GC vials, and then injected into the GC. $\mathrm{NH}_{4}{ }^{+}, \mathrm{TN}, \mathrm{PO}_{4}{ }^{3-}$, and $\mathrm{K}^{+}$were measured using a spectrophotometer and HACH Lange LCK cuvette test system (LCK-303 $\mathrm{NH}_{4}{ }^{+}, \mathrm{LCK}-338 \mathrm{TN}, \mathrm{LCK}-049 \mathrm{PO}_{4}{ }^{3-}$, and LCK-228 $\mathrm{K}^{+}$). Before the analysis samples were diluted 10-30 times to meet the measuring range of the LCK cuvette. Trace metals were measured by atomic absorption spectrometry equipped with a graphite tube atomizer (AAS, Agilent AA-200 series graphite furnace atomic absorption spectrometer, Agilent Technologies, Santa Clara, CA). AAS was calibrated using standard solutions from Agilent 
and hollow cathode lamp also from Agilent were used for each of the metals, Fe, Ni, Co, and Mn.

\subsection{Performance parameters}

Gas retention time (GRT) was calculated based on the total gas flowrate at the inlet of the reactor and empty bed, as shown in Eq. 1 . Here, $V_{r}$ is the empty packed bed volume and $F_{H_{2}}, F_{C_{2}}$, and $F_{N_{2}}$ are the inlet flowrate of the gas components $\mathrm{H}_{2}, \mathrm{CO}_{2}$, and $\mathrm{N} 2$, respectively, in $\mathrm{NmL} / \mathrm{min}$.

$$
G R T=\frac{V_{r}}{F_{H_{2}}+F_{C O_{2}}+F_{N_{2}}}
$$

To analyze the reactor performance in terms of methane production, specific methane production capacity $\left(\mathrm{PC}, \mathrm{Nm}^{3} / \mathrm{m}^{3} \mathrm{~d}\right.$ ) was calculated as shown in Eq. 2 . Here, $F_{\text {out }}(\mathrm{NmL} / \mathrm{min})$ is the total gas flowrate at the reactor outlet and $\mathrm{C}_{\mathrm{CH}_{4}}$ is the $\mathrm{CH}_{4}$ composition at the reactor outlet.

$$
P C=\frac{1440 F_{\text {out }} C_{C H_{4}}}{V_{r}}
$$

To analyze the conversion of $\mathrm{H}_{2}$ removal efficiency ( $\mathrm{RE}, \%$ ) was calculated, as shown in Eq. 3. Here, $C_{H_{2}}$ is the $\mathrm{H}_{2}$ composition at the reactor outlet

$$
R E=\frac{F_{H_{2}}-F_{\text {out }} C_{H_{2}}}{F_{H 2}} 100
$$

\subsection{Startup and operating procedures}

Details about the input parameters and experimental trials conducted are given in Table 2. The reactor was started using the direct inoculation methods as outlined in [25]. A mix of $\mathrm{H}_{2}, \mathrm{CO}_{2}$, and $\mathrm{N}_{2}$ was used as the inlet gas to the reactors. $\mathrm{N}_{2}$ was added in the inlet gas to simulate the feed gas as biogas, where $\mathrm{N}_{2}$ asserts an equivalent partial pressure in the feed gas as that of $\mathrm{CH}_{4}$ in the case of a biogas feed. However, during the startup and enrichment period, only $\mathrm{H}_{2}$ and $\mathrm{CO}_{2}$ were fed as inlet gas to the reactors. This enables a higher partial pressure of substrate $\mathrm{H}_{2}$ and $\mathrm{CO}_{2}$ that assists the enrichment and development of biofilm in the BTF reactors. After the startup period, GRT reduction trials were conducted, where the objective was the incremental increase in the gas feed flowrate and in turn to maximize the PC. After that, the nutrient consumption and supply trials were conducted. Here a distinction needs to be made, the term nutrient dosing is used for the addition and/or supplementation of the nutrients in the nutrient media sump to maintain the concentration of the essential nutrients in the sump. During the nutrient consumption trials the concentrations of the nutrients in the sump were measured, and their consumption was recorded over time. The term nutrient supply 
Table 2: Set of experimental trials with details of feed gas flowrate and gas retention time (GRT).

\begin{tabular}{lccc}
\hline Trial description & Days & $\begin{array}{c}\text { Feed gas flowrate } \\
\mathrm{H}_{2}: \mathrm{CO}_{2}: \mathrm{N}_{2} \\
\text { (all values in } \mathrm{NmL} / \mathrm{min})\end{array}$ & GRT (min) \\
\hline Startup and enrichment & $0-7$ & $4.0: 1.11: 0$ & 98.6 \\
GRT Reduction trial & $7-64$ & $4.0: 1.11: 1.0$ & 82.5 \\
& $65-85$ & $5.24: 1.34: 2.0$ & 59.2 \\
Nutrient consumption trial & $86-115$ & $12.7: 3.4: 3.5$ & 25.7 \\
Nutrient dosing trial & $116-281$ & $8.0: 1.66: 2.0$ & 43.2 \\
Nutrient supply method trial & $282-303$ & $12.7: 3.4: 3.5$ & 25.7 \\
Biomethanation trial & $304-408$ & $12.7: 3.4: 3.5$ & 25.7 \\
& $409-436$ & $16: 4.2: 0$ & 24.9 \\
& $437-450$ & $24: 6.22: 0$ & 16.7 \\
\hline
\end{tabular}

refers to the method of supplying the media over the packed bed. Three nutrient supply methods were tested, namely, continuous trickling at the top, flushing, and flooding. Flushing was defined as trickling at $400 \mathrm{~mL} / \mathrm{min}$ (flux $10.5 \mathrm{~m}^{3} / \mathrm{m}^{2} \mathrm{~h}$ ) for $3 \mathrm{~min}$, a method of a relatively high rate of trickling to wet a larger fraction of the packing. Flooding was the method of filling the whole reactor with the nutrient media till the top of the packing, the nutrient media was completely drained immediately afterward.

\section{Results and Discussions}

\subsection{Enrichment and GRT reduction trail}

The reactor started producing $\mathrm{CH}_{4}$ on the second day and on day 5 its concentration reached a maximum value of $28.5 \mathrm{~mole} \%\left(C_{C H_{4}}\right.$ at the reactor outlet. This showed that the enrichment of the hydrogenotrophic methanogens has started. After that $\mathrm{N}_{2}$ feed to the reactor was started along with the start of GRT reduction trial. The results of the performance parameters are shown in Figure 2. In the first step, the GRT was $82.5 \mathrm{~min}$ and the $\mathrm{H}_{2}$ concentration at the outlet kept decreasing indicating increased activity of the hydrogenotrophic methanogens. From day 22 there was an almost complete conversion of $\mathrm{H}_{2}$, this shows that the 7 days of enrichment period was insufficient, and it took 22 days for the development of sufficient biofilm that resulted in the complete conversion of $\mathrm{H}_{2}$. These results are in agreement with the direct inoculation method reported in [25], where a rapid increase in $\mathrm{CH}_{4}$ was observed during the first 10 days and a steady production was achieved after 25 days. From day 22 onwards the conversion remained stable with an average PC of $1.7 \mathrm{Nm}^{3} / \mathrm{m}^{3} \mathrm{~d}$ and average $C_{N_{2}+C H_{4}}$ of $87.7 \%$. On day 65 the GRT was decreased to $59.2 \mathrm{~min}$, the reactor performance remained stable at 
this trial with an average PC of $3.65 \mathrm{Nm}^{3} / \mathrm{m}^{3} \mathrm{~d}$ and average $C_{N_{2}+C H_{4}}$ of $94.2 \%$. The outlet gas quality was improved during this period as the feed gas ratios were adjusted to reduce the unconverted $\mathrm{CO}_{2}$ at the reactor outlet. During days 86 to 115 the feed gas flowrate was further increased and GRT was set at $25.7 \mathrm{~min}$. The PC increased to $6.7 \mathrm{Nm}^{3} / \mathrm{m}^{3} \mathrm{~d}$ initially, however, there was an incomplete conversion of $\mathrm{H}_{2}$. The $C_{H_{2}}$ at the reactor outlet kept increasing afterward, Figure $1 \mathrm{~b}$, which showed that the activity of the hydrogenotrophic methanogens was decreasing. The average PC achieved during this period was $5.37 \mathrm{Nm}^{3} / \mathrm{m}^{3} \mathrm{~d}$. As seen in Figure $2 \mathrm{c}$, the $\mathrm{pH}$ of the nutrient media sump was within the normal operating range $(<8.5)$ and the VFA concentration was also insignificant $(<0.1 \mathrm{mg} / \mathrm{L})$. The temperature of the reactor was also maintained at an average value of $52{ }^{\circ} \mathrm{C}$ during this period. Before the start of the trial at GRT $25.7 \mathrm{~min}$, nutrient media was added two times to maintain the liquid level in the media sump: $350 \mathrm{~mL}$ on day 59 and $200 \mathrm{~mL}$ on day 79. The liquid level decreases due to the periodic cleaning of the external mesh filter. On day 109, $150 \mathrm{~mL}$ of nutrient media was added that relatively improved the $\mathrm{H}_{2}$ conversion, and $C_{H_{2}}$ decreased from $42 \%$ to $35 \%$, however, this effect was short-lived and the $C_{H_{2}}$ increased again to $<40 \%$ on day 114 .

The objective of the GRT reduction trial was to find the limits for stable conversion and maximum PC. During this trial the GRT was reduced stepwise and it showed that the supply of the nutrient could be the bottleneck in increasing the PC and maintaining the quality of the upgraded biogas.

\subsection{Estimation of nutrient limitation}

From day 116 to 281 nutrient limitation trials were conducted, the objective was to find whether the trickling or supply method is the limiting factor or the concentration level of the nutrients in the media sump are the limiting factor. To stabilize the reactor the gas feed flowrate to the reactor was reduced and GRT was increased from $25.7 \mathrm{~min}$ to $43.2 \mathrm{~min}$. This temporality improved the $\mathrm{H}_{2}$ conversion but overall, the $C_{H_{2}}$ kept increasing at the outlet of the reactor, as shown in Figures 2a and $2 \mathrm{~b}$.

\subsubsection{Nutrient supply method}

The nutrient media was trickled continuously from the top of the reactor at a flowrate of $10 \mathrm{~mL} / \mathrm{min}$ (flux $0.262 \mathrm{~m}^{3} / \mathrm{m}^{2} \mathrm{~h}$ ). It might be possible that there was channeling due to which only a limited area of the packing was getting the nutrient supply. To investigate this limitation flushing trials were conducted, where nutrient media was trickled at a high flowrate of $400 \mathrm{~mL} / \mathrm{min}$ (flux $10.5 \mathrm{~m}^{3} / \mathrm{m}^{2}$ h) for 3 mins. The idea was to disturb the channeling and to enable the nutrient supply to a wider section of the packing. On day 140 the reactor was flushed, as can be seen in Figure $2 \mathrm{~b}$ this resulted in decreasing the $C_{H_{2}}$ from $32 \%$ to $19 \%$. However, this improvement in conversion was short-lived and $C_{H_{2}}$ increased again. This indicated that channeling might be a factor and the nutrient supply could 

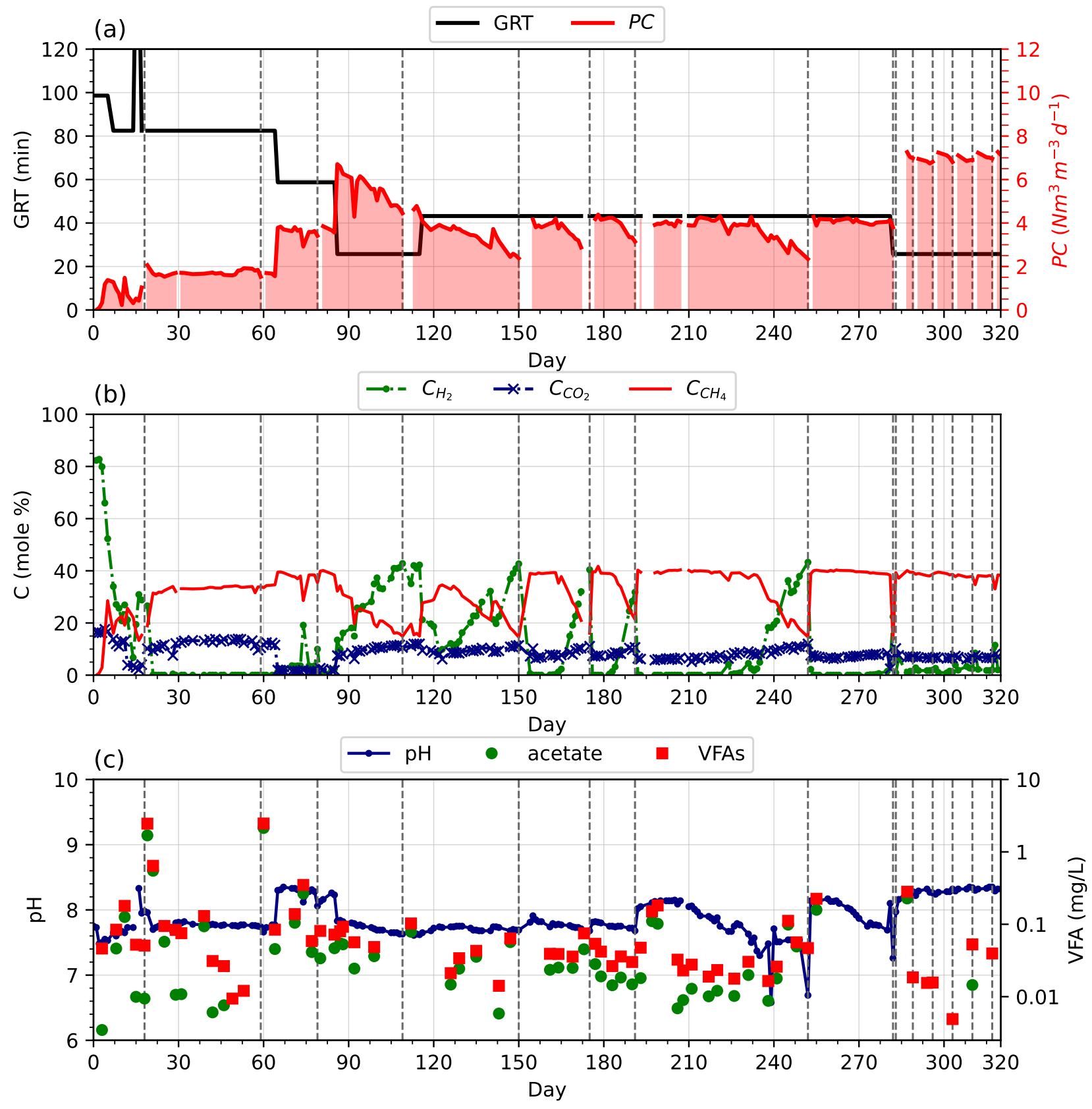

Figure 2: Figure showing the overall performance of the reactor during the GRT reduction and nutrient consumption trials. (a) GRT ( $\mathrm{min})$ - gas retention time, PC $\left(\mathrm{Nm}^{3} / \mathrm{m}^{3} \mathrm{~d}\right)$ specific $\mathrm{CH}_{4}$ production capacity. (b) $C_{H_{2}}(\operatorname{mole} \%)-\mathrm{H}_{2}$ gas composition at the reactor outlet, $C_{\mathrm{CO}_{2}}(\mathrm{~mole} \%)-\mathrm{CO}_{2}$ gas composition at the reactor outlet, and $C_{N_{2}+\mathrm{CH}_{4}}-$ sum of $\mathrm{N}_{2}$ and $\mathrm{CH}_{4}$ composition at the reactor outlet, as an indicator of the outlet gas quality. (c) VFA $(\mathrm{mg} / \mathrm{L})$ - total volatile fatty acids. Vertical dashed lines indicate the events of nutrient media addition in the nutrient media sump.

be improved by routinely flushing the reactor. Hence, from day 150 to 190 the reactor was flushed every second day. During this the fresh media was added on days 150 and 175 with the following 
procedure: $100 \mathrm{~mL}$ of was removed and $200 \mathrm{~mL}$ of the fresh media was added in the sump. As can be seen in Figure $2 b$, the $\mathrm{H}_{2}$ conversion improved significantly after media addition on days 150 and 175, the $C_{H_{2}}$ reduced to almost 0 . However, the $C_{H_{2}}$ remained stable for approx. 10 days and afterward it started increasing again. The routine of flushing the reactor every second day was carried out during this period ensured supply over a wider fraction of the packing. Considering this, the decrease in conversion showed that the concentration of nutrients could have decreased over time that resulted in lowering the activity of methanogens. Hence, the concentration levels of the nutrients were measured over time.

\subsubsection{Critical nutrients}

From day 191 to 281 nutrient concentrations were routinely measured to identify the essential nutrients and to estimate the minimum or critical concentration of these nutrients. The flushing routine was changed from once every second day to once every week. The media sump was cleaned and refilled twice during this period. First, on day 191 the media sump was cleaned and refilled with a fresh batch of media. The feed gas flowrate and all other parameters were kept the same. From day 211 the concentrations of $\mathrm{NH}_{4}{ }^{+}, \mathrm{K}^{+}, \mathrm{PO}_{4}{ }^{3-}, \mathrm{Fe}, \mathrm{Ni}, \mathrm{Co}$, and $\mathrm{Mn}$ were measured routinely, the results are shown in Figure 3. As can been seen in Figure 3, right after the media replacement activity on day 191, there was an almost complete conversion of $\mathrm{H}_{2}$, and it remained stable till day 224. $C_{H_{2}}$ started increasing afterward and reached $43 \%$ by day 252. During this period, i.e. day 211 to 228 , there was a relative decrease in the concentration of $\mathrm{NH}_{4}{ }^{+}$and Fe. During these 15 days, the concentration of $\mathrm{NH}_{4}{ }^{+}$reduced by $95 \%$ from $0.601 \mathrm{~g} / \mathrm{L}$ on day 211 to $0.032 \mathrm{~g} / \mathrm{L}$ on day 224 and Fe concentration dropped from $2.549 \mathrm{mg} / \mathrm{L}$ to $1.306 \mathrm{mg} / \mathrm{L}$, a $48 \%$ change. On day 252 the media sump and media line filter were cleaned for the second time and $300 \mathrm{~mL}$ of the nutrient media mixed with $150 \mathrm{~mL}$ of deionized water were added to the sump. $\mathrm{H}_{2}$ conversion improved after the media addition and remained stable till day 280. Again, $\mathrm{NH}_{4}{ }^{+}$and Fe were the two nutrients with a significant decrease in the concentration level; $\mathrm{NH}_{4}{ }^{+}$concentration dropped from $0.634 \mathrm{~g} / \mathrm{L}$ to $0.002 \mathrm{mg} / \mathrm{L}$ on day 280 , a drop of $99 \%$, and $\mathrm{Fe}$ concentration dropped from $3.971 \mathrm{mg} / \mathrm{L}$ to $0.842 \mathrm{mg} / \mathrm{L}$, a drop of $79 \%$. The concentrations of other measured nutrients remained relatively unchanged, which indicated that the concentration of $\mathrm{NH}_{4}{ }^{+}$ and Fe could be the significant parameter for the methanogens in BTF. However, this does not mean that other trace metals are not essential; their significance for the methanogens and for the overall anaerobic digestion process have been reviewed in detail $[16,21,26]$.

In this study, the critical level of $\mathrm{NH}_{4}{ }^{+}$and $\mathrm{Fe}$ was estimated as a minimum concentration below which the activity of the hydrogenotrophic methanogenesis starts getting affected. For $\mathrm{NH}_{4}{ }^{+}$and $\mathrm{Fe}$, the 


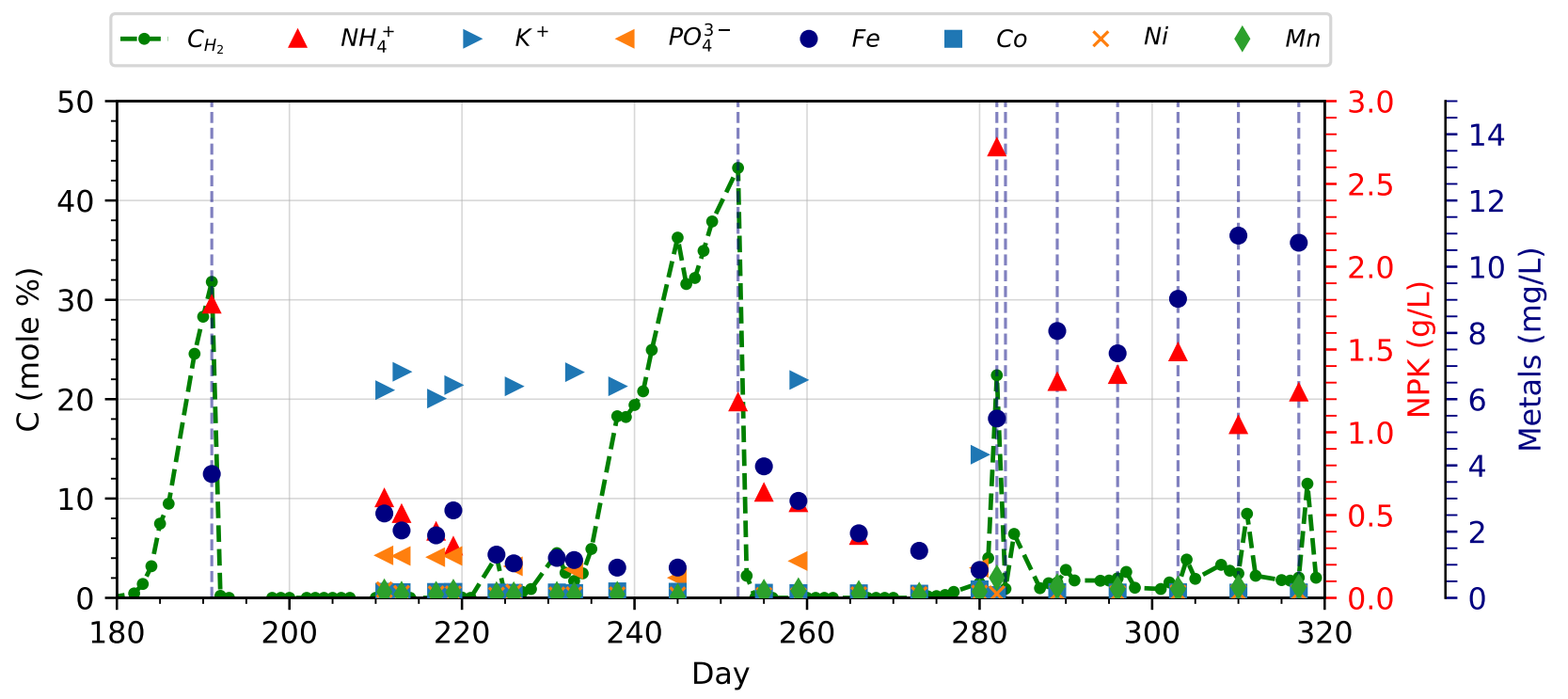

Figure 3: Nutrient composition in the nutrient media sump of the reactor. $C_{H_{2}}(\mathrm{~mole} \%)-$ $\mathrm{H}_{2}$ gas composition at the reactor outlet, NPK - stands for nitrogen $\left(\mathrm{NH}_{4}{ }^{+}\right)$, phosphorous $\left(\mathrm{PO}_{4}{ }^{3-}\right)$, and potassium $\left(\mathrm{K}^{+}\right)$.

critical levels were estimated as $0.3 \mathrm{~g} / \mathrm{L}$ and $1.5 \mathrm{mg} / \mathrm{L}$, respectively. Dupnock and Deshusses, (2019) used artificial nutrient media in their study for BTF and reported similar values, where $\mathrm{NH}_{4}{ }^{+}$and Fe concentrations higher than $1 \mathrm{~g} / \mathrm{L}$ and $2 \mathrm{mg} / \mathrm{L}$, respectively were reported as optimal. They reported a $41 \%$ increase in $\mathrm{PC}$ after the $\mathrm{NH}_{4}{ }^{+}$and Fe concentrations in the nutrient media were optimized. For wastewater treatment by an anaerobic digester, a minimum requirement of Fe was estimated as 1.9 $\mathrm{mg} / \mathrm{L}[15]$.

\subsection{Optimizing the nutrient supply method}

As was shown in section 3.2.1, the flushing of the reactor increased the $\mathrm{H}_{2}$ conversion which indicated that the method of supplying the nutrients over the packing of the BTF has a significant effect on the conversion. An effective nutrient supply method ensures the nutrients supply to a wider section of the packing material that enables a larger active biofilm area. In this section results from the systemic investigation of three different methods of nutrient supply in a BTF setup are reported. The three options for the nutrient supply method were continuous trickling, flushing, and flooding. The term flushing is defined as a high rate of trickling for a short while and the term flooding refers to the method of filling the column with media such that all the packing is submerged. The feed gas flowrate had to be stopped during the flooding activity. The following set of trials were conducted: (i) continuous trickling at different flowrates, (ii) flushing with continuous trickling, (iii) flushing with no trickling, (iv) flooding with continuous trickling, and (v) flooding with no trickling. The routine of 
Table 3: Effect of continuous nutrient media trickling flowrate on the BTF performance.

\begin{tabular}{lcccccc}
\hline Days & $\begin{array}{c}\text { Flowrate of } \\
\text { Trickling } \\
(\mathrm{mL} / \mathrm{min})\end{array}$ & $\begin{array}{c}\text { Liquid Flux } \\
\left(\mathrm{m}^{3} / \mathrm{m}^{2} \mathrm{~h}\right)\end{array}$ & GRT $(\mathrm{min})$ & $\begin{array}{c}\text { Average } \\
C_{H_{2}}(\mathrm{~mole} \\
\%)\end{array}$ & $\begin{array}{c}\text { Average } \mathrm{H}_{2} \\
\text { RE }(\%)\end{array}$ & $\begin{array}{c}\text { Average PC } \\
\left(\mathrm{Nm}^{3} / \mathrm{m}^{3}\right. \\
\mathrm{d})\end{array}$ \\
\hline $282-302$ & 10 & 0.262 & 50.41 & 1.67 & 99.15 & 7.0 \\
$303-310$ & 30 & 0.786 & 16.8 & 2.57 & 98.6 & 6.91 \\
$311-317$ & 60 & 1.572 & 8.4 & 3.35 & 98.16 & 7.06 \\
$318-324$ & 90 & 2.358 & 5.6 & 4.32 & 97.54 & 6.90 \\
$325-331$ & 120 & 3.144 & 4.2 & 12.69 & 93.02 & 6.30 \\
$332-338$ & 150 & 3.930 & 3.4 & 7.06 & 96.29 & 6.70 \\
$339-345$ & 200 & 5.240 & 2.5 & 15.79 & 90.82 & 6.05 \\
\hline
\end{tabular}

weekly nutrient dosing was continued during these trials ensuring the nutrient concentration levels were higher than the minimum levels estimated in section 3.2.2.

\subsubsection{Effect of flowrate of continuous trickling}

Flowrate of the continuous media trickling was varied from $10 \mathrm{~mL} / \mathrm{min}$ to $200 \mathrm{~mL} / \mathrm{min}$. Each setting of the flowrate was maintained for 7 days and the average values of performance parameters measured are given in Table 3. $\mathrm{H}_{2}$ conversion reduced with an increase in the trickling flowrate. Taking the 10 $\mathrm{mL} / \mathrm{min}$ as the base case, the $C_{\mathrm{H}_{2}}$ increased from an average value of $1.96 \%$ at $10 \mathrm{~mL} / \mathrm{min}$ of trickling flowrate to $15.79 \%$ at $200 \mathrm{~mL} / \mathrm{min}$ of trickling flowrate. Similarly, $\mathrm{RE}$ of $\mathrm{H}_{2}$ reduced from $98.9 \%$ to $90.82 \%$ and PC reduced from $7.0 \mathrm{Nm}^{3} / \mathrm{m}^{3} \mathrm{~d}$ to $6.05 \mathrm{Nm}^{3} / \mathrm{m}^{3} \mathrm{~d}$. A similar correlation of decrease in PC with an increase in trickling flowrate was reported by [5]. The increased trickling flowrate results in a thicker water film on top of the hydrogenotrophic biofilm. As a result, it increases the resistance to mass transfer for the feed gases $\mathrm{H}_{2}$ to reach the active hydrogenotrophic methanogens inside the biofilm.

\subsubsection{Flushing vs flooding}

Figure 4 shows the results of the flushing and flooding trials, where the total gas flowrate at the reactor outlet, $F_{\text {out }}$, is used as an indicator of reactor performance. The $F_{\text {out }}$ was recorded continuously using the $\mathrm{BPC}^{\circledR} \mu$ Flow Gas flowmeter connected with a data logger. Because there was a net reduction of gas moles due to the biomethanation reaction, a lower flowrate at the reactor outlet indicated a higher conversion while higher flowrate values indicated a relatively lower conversion. Right after, either the flooding or flushing there was a transient period of relatively higher flowrate at the reactor outlet that showed that both methods lowered the conversion for a certain duration. This was due to the buildup of a thicker water film that increased the mass transfer resistance. The conversion recovers after the media had drained down the sump. For the case of non-continues trickling, both flooding and flushing showed a transient period that lasted for approx. $24 \mathrm{~h}$, as shown in Figure $4 \mathrm{a}$. For the 

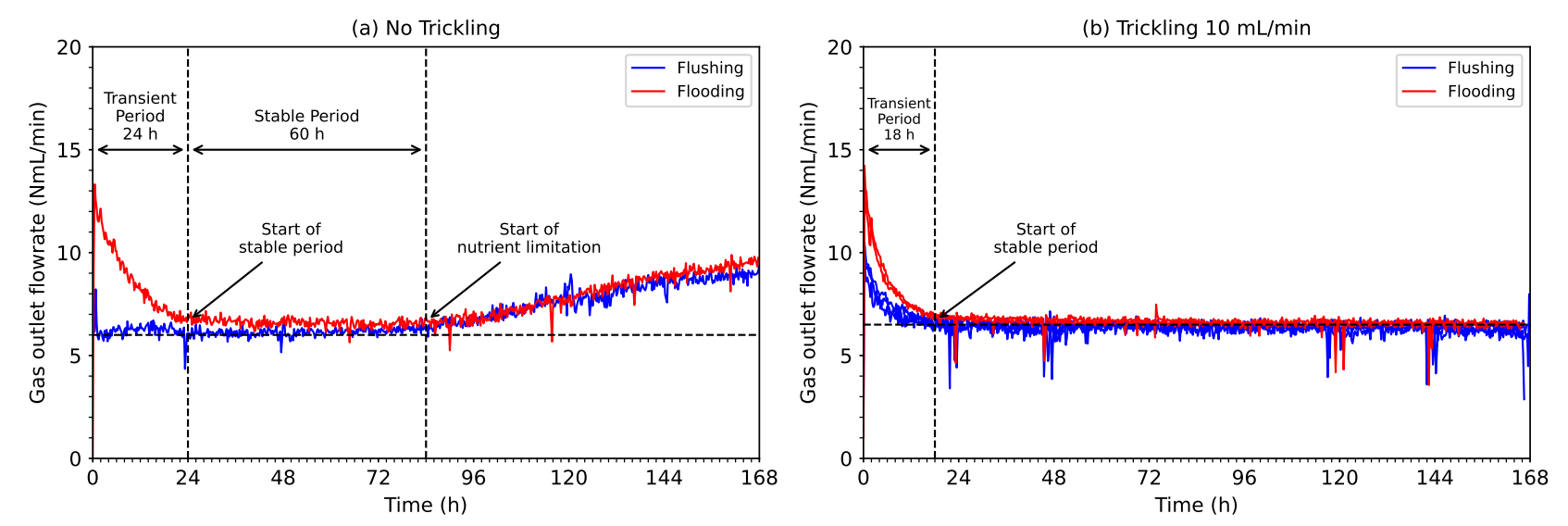

Figure 4: Comparison of two nutrient supply methods-flushing and flooding. (a) no continuous trickling after flushing or flooding, (b) continuous trickling at $10 \mathrm{~mL} / \mathrm{min}$ after flushing or flooding.

case where continuous trickling was started after the flushing and flooding the transient period was $18 \mathrm{~h}$, as shown in Figure 1b. This indicates that the continuous trickling might facilities the draining of the liquid media from the packing.

The trials with no trickling after the flushing and flooding showed the efficacy of these nutrient supply methods over time. The results showed that after the transient period is over the conversion in the reactor is stable for a limited time, as shown in Figure 4a. The stable period was approx. $60 \mathrm{~h}$ after which the outlet gas flowrate started increasing indicating the beginning of nutrient limitation. In comparison, in the trials where media was continuously trickled after the flushing and flooding the stable period lasted for $150 \mathrm{~h}$, as shown in Figure 1b, after which the flooding or flushing activity was done again. This showed that the combined method of continuous media trickling along with either the flushing or flooding was the best method for the supply of nutrients. Using this combined methodology, the transient period was relatively shorter, and the stable period was increased from 60 $\mathrm{h}$ to $150 \mathrm{~h}$.

Comparing the flushing and flooding, no relative difference was found between these two methods of nutrient supply in terms of their efficacy of nutrient supply. However, there are aspects of operating and capital cost that needs to be determined to select among these methods of nutrient supply. The flooding method will require a separate vessel of at least equal volume of the BTF reactor to store the nutrient media for flooding. This will increase the capital cost of the biomethanation system. The flushing method does not require additional vessels however, a high flowrate pump will be required. Moreover, the flooding method ensures a complete wetting of the packing material and ensures the supply of nutrients over all the packing material. Hence, inoculation of the BTF with flooding is 
recommended as it will ensure the formation of the biofilm over all the packing material.

As was discussed in section 3.2.1, the method of supplying the nutrients with only continuous trickling at a relatively low flowrate could lead to channeling and reduced activity of the biofilm. Hence, ensuring the nutrient media supply using the relatively vigorous method of flushing or flooding is necessary. However, they cause the conversion to reduce for the duration of the transient period. This means that a biomethanation system consisting of a single BTF reactor cannot maintain a steady operation or $\mathrm{CH}_{4}$ productivity. To overcome this shortcoming, a system of two or more BTF can be designed that undergo the vigorous nutrient supply method of flooding or flushing at alternative times. This system can be operated using a feed gas flowrate control scheme that shifts the feed gas flowrate to the reactor operating at a stable period and reduces the feed gas flowrate from the reactor that is under the transient period. Overall, the feed gas control scheme can ensure a steady conversion and outlet flowrate from the biomethanation system.

The effect of the thickness of water film on BTF performance was investigated by [9] where they compared the PC with continuous nutrient trickling at a flux of $1.36 \mathrm{~m}^{3} / \mathrm{m}^{2} \mathrm{~h}$ and no trickling. They reported a 20\% increase in PC without trickling as compared to the trickling. This improvement effect was attributed to direct gas to biofilm contact where the mass transfer resistance due to water film is not present. The results of this study also show the same effect where PC decrease with increasing the trickling rate. It was also shown in this study that the case of no trickling is not sustainable for long period. However, intermittent supply of the nutrient can be adopted, where the reactor is either flushed or flooded at controlled intervals.

\subsection{Biomethanation trial}

During the biomethanation trial, the feed gas consisted only of $\mathrm{H}_{2}$ and $\mathrm{CO}_{2}$. The objective was to investigate the effect of relatively higher partial pressure of reacting gases, $\mathrm{H}_{2}$ and $\mathrm{CO}_{2}$, in the absence of N2 which is an inert gas component. The relatively higher partial pressure of the reacting gases could lead to higher absorption of reacting components in the biofilm and higher rates of reaction. The biomethanation trial was conducted at a high gas feed rate to GRT of 24.9 and $16.7 \mathrm{~min}$ and the results are shown in Figure 5. On average PC was $8.51 \pm 0.56 \mathrm{Nm}^{3} / \mathrm{m}^{3} \mathrm{~d}$ at GRT of $24.9 \mathrm{~min}$, which was $21 \%$ higher than the PC of $7.0 \pm 0.17 \mathrm{Nm}^{3} / \mathrm{m}^{3} \mathrm{~d}$ achieved at a similar GRT of $25.7 \mathrm{~min}$ but had $\mathrm{N} 2$ the feed gas. This showed the effect of partial pressure of the reacting gases that leads to higher absorption and conversion in the absence of the inert component. The average PC further increased to $9.44 \pm 0.50 \mathrm{Nm}^{3} / \mathrm{m}^{3} \mathrm{~d}$ at GRT of 16.7 . 

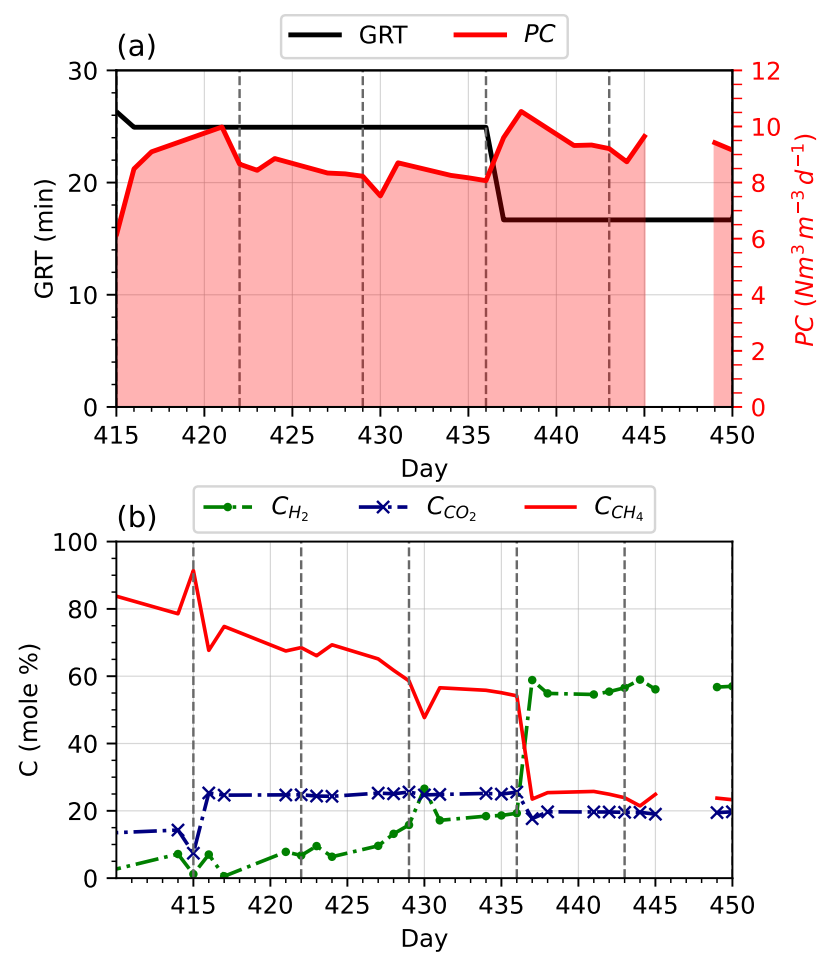

Figure 5: Figure showing the overall performance of the reactor during the biomethanation trials. (a) GRT (min) - gas retention time, $\mathrm{PC}$ - specific $\mathrm{CH}_{4}$ production capacity $\left(\mathrm{Nm}^{3} / \mathrm{m}^{3}\right.$ d). (b) $C_{H_{2}}($ mole $\%)-\mathrm{H}_{2}$ gas composition at the reactor outlet, $C_{C_{2}}(\operatorname{mole} \%)-\mathrm{CO}_{2}$ gas composition at the reactor outlet, and $\mathrm{C}_{\mathrm{CH}_{4}}(\mathrm{~mole} \%)-\mathrm{CH}_{4}$ gas composition at the reactor outlet.

During the biomethanation trial, there was unreacted $\mathrm{H}_{2}$ and $\mathrm{CO}_{2}$ at the reactor outlet, $\mathrm{RE}$ was $96.1 \%$ and $67.6 \%$ at GRT of 24.9 and $16.7 \mathrm{~min}$, respectively. This indicated that the feed gases were available over the whole length of the packing in the reactor, hence the $\mathrm{CH}_{4}$ formation was not limited by the unavailability of the substrate. This also means that the PC value achieved at GRT of 16.7 was the maximum possible for this size and type of packing material and reactor, considering that the whole packing contained an active biofilm of hydrogenotrophic methanogens. The reason for unconverted $\mathrm{H}_{2}$ and $\mathrm{CO}_{2}$ at the same GRT compared to when the feed was $\mathrm{H}_{2}, \mathrm{CO}_{2}$, and N2, is the increased $\mathrm{H}_{2}$ and $\mathrm{CO}_{2}$ flow due to the same GRT.

\subsection{Overall reactor performance}

In an earlier study BTF reactor using the PCM and polyurethane foam as packing material was tested. The PCM used was only coarse filtered through $500 \mu \mathrm{m}$ mesh, which resulted in clogging the reactor after 215 days of operation. During this study pretreatment of PCM was carried to filter it through $125 \mu \mathrm{m}$. Also, an external filter was installed in the nutrient media line, as shown in Figure 1, which was cleaned routinely. With these modifications, the reactor was successfully operated for 450 days. 
This showed that the continuous operation of the BTF could be extended by adopting a pretreatment method for PCM and with the use of an inline filter. The same approach applies to other solid containing nutrient media, for example, anaerobic digestate.

The maximum average PC achieved in this study was $7.0 \pm 0.17 \mathrm{Nm}^{3} / \mathrm{m}^{3} \mathrm{~d}$ with the inert gas present in the feed gas and an average outlet gas quality of $C_{N_{2}+\mathrm{CH}_{4}}$ of $91 \% \pm 1.7 \%$ was achieved. During the biomethanation trail, the maximum average PC was $9.44 \mathrm{Nm}^{3} / \mathrm{m}^{3} \mathrm{~d}$, however, this was achieved at GRT of $16 \mathrm{~min}$ and without complete conversion of $\mathrm{H}_{2}$ and $\mathrm{CO}_{2}$. These values of $\mathrm{PC}$ are lower as compared to the maximum reported in the literature for BTF, for example, PC of $15.4 \mathrm{Nm}^{3} / \mathrm{m}^{3} \mathrm{~d}$ was reported by [10]. The relatively lower PC achieved in this study could be due to the packing material, as in the earlier study a PC of $8.54 \pm 0.47 \mathrm{Nm}^{3} / \mathrm{m}^{3} \mathrm{~d}$ was achieved [24], that used a similar BTF design and PCM as nutrient media but had polyurethane foam as the packing material.

\section{Conclusion}

The installation of an external filter and pretreatment of the pasteurized cow manure led to 450 days of continuous BTF operation without clogging. $\mathrm{NH}_{4}{ }^{+}$and Fe were essential nutrients and their concentration of nutrients can be controlled using either a routine or continuous replacement of the nutrient media. Continuously trickling at a low flowrate together with periodical flushing or flooding was found to be an effective strategy for the nutrient supply; although both flushing and flooding affect the $\mathrm{CH}_{4}$ productivity in the hours after. This effect needs to be considered at a system level design of BTF.

\section{Acknowledgment}

This work was supported by the Energi teknologisk Udviklings- og Demonstrations program (EUDP) under the project "eFuel-electro fuel from a biotrickling filter".

\section{Author statement}

Muhammad Tahir Ashraf: writing - original draft, conceptualization, methodology, investigation, formal analysis, visualization.

Lars Yde: conceptualization, methodology, resources, writing - review.

Jin Mi Triolo: supervision, writing - review.

Henrik Wenzel: supervision, conceptualization, methodology. 


\section{References}

[1] Manuel Götz, Jonathan Lefebvre, Friedemann Mörs, Amy McDaniel Koch, Frank Graf, Siegfried Bajohr, Rainer Reimert, and Thomas Kolb. Renewable Power-to-Gas: A technological and economic review. Renewable Energy, 85:1371-1390, 2016. doi: 10.1016/j.renene.2015.07.066.

[2] Malte Behrens, Michael Bowker, and Graham Hutchings. Research needs towards sustainable production of fuels and chemicals, 2020. URL https://www.energy-x.eu/ research-needs-report/.

[3] Herib Blanco, Wouter Nijs, Johannes Ruf, and André Faaij. Potential of Power-to-Methane in the EU energy transition to a low carbon system using cost optimization. Applied Energy, 232 (August):323-340, 2018. doi: 10.1016/j.apenergy.2018.08.027.

[4] Daan Peters, Kees van der Leun, Wouter Terlouw, Juriaan van Tilburg, Tom Berg, Matthias Schimmel, Irina van der Hoorn, Maud Buseman, Maarten Staats, Mark Schenkel, and Goher Ur Rehman Mir. Gas Decarbonisation Pathways 2020-2050, 2020. URL https:// gasforclimate2050.eu/?smd_process_download=1\&download_id=339.

[5] M. Burkhardt, T. Koschack, and G. Busch. Biocatalytic methanation of hydrogen and carbon dioxide in an anaerobic three-phase system. Bioresource Technology, 178:330-333, 2015. doi: 10.1016/j.biortech.2014.08.023.

[6] Lydia Rachbauer, Gregor Voitl, Günther Bochmann, and Werner Fuchs. Biological biogas upgrading capacity of a hydrogenotrophic community in a trickle-bed reactor. Applied Energy, 180: 483-490, 2016. doi: 10.1016/j.apenergy.2016.07.109.

[7] Dietmar Strübing, Andreas B. Moeller, Bettina Mößnang, Michael Lebuhn, Jörg E. Drewes, and Konrad Koch. Anaerobic thermophilic trickle bed reactor as a promising technology for flexible and demand-oriented H2/CO2 biomethanation. Applied Energy, 232(July):543-554, 2018. doi: 10.1016/j.apenergy.2018.09.225.

[8] Mads Ujarak Sieborg, Brian Dahl Jønson, Muhammad Tahir Ashraf, Lars Yde, and Jin Mi Triolo. Biomethanation in a thermophilic biotrickling filter using cattle manure as nutrient media. Bioresource Technology Reports, 9:100391, 2020. doi: 10.1016/j.biteb.2020.100391.

[9] Trisha L. Dupnock and Marc A. Deshusses. Detailed investigations of dissolved hydrogen and hydrogen mass transfer in a biotrickling filter for upgrading biogas. Bioresource Technology, 290 
(July):121780, 2019. doi: 10.1016/j.biortech.2019.121780.

[10] Dietmar Strübing, Bettina Huber, Michael Lebuhn, Jörg E. Drewes, and Konrad Koch. High performance biological methanation in a thermophilic anaerobic trickle bed reactor. Bioresource Technology, 245(June):1176-1183, 2017. doi: 10.1016/j.biortech.2017.08.088.

[11] M. A. Voelklein, Davis Rusmanis, and J. D. Murphy. Biological methanation: Strategies for in-situ and ex-situ upgrading in anaerobic digestion. Applied Energy, 235(November 2018):1061-1071, 2019. ISSN 03062619. doi: 10.1016/j.apenergy.2018.11.006. URL https://doi .org/10.1016/j . apenergy .2018.11.006.

[12] Ilaria Bassani, Panagiotis G. Kougias, Laura Treu, Hugo Porté, Stefano Campanaro, and Irini Angelidaki. Optimization of hydrogen dispersion in thermophilic up-flow reactors for ex situ biogas upgrading. Bioresource Technology, 234:310-319, 2017. doi: 10.1016/j.biortech.2017.03.055.

[13] Konstantinos Asimakopoulos, Martin Kaufmann-Elfang, Christoffer Lundholm-Høffner, Niels B.K. Rasmussen, Antonio Grimalt-Alemany, Hariklia N. Gavala, and Ioannis V. Skiadas. Scale up study of a thermophilic trickle bed reactor performing syngas biomethanation. Applied Energy, 290(March), 2021. doi: 10.1016/j.apenergy.2021.116771.

[14] P. Scherer, H. Lippert, and G. Wolff. Composition of the major elements and trace elements of 10 methanogenic bacteria determined by inductively coupled plasma emission spectrometry. Biological Trace Element Research, 5(3):149-163, 1983. doi: 10.1007/BF02916619.

[15] Masanobu Takashima, Kohji Shimada, and Richard E. Speece. Minimum Requirements for Trace Metals (Iron, Nickel, Cobalt, and Zinc) in Thermophilic and Mesophilic Methane Fermentation from Glucose. Water Environment Research, 83(4):339-346, 2011. doi: 10.2175/106143010x12780288628895.

[16] Jennifer B. Glass and Victoria J. Orphan. Trace metal requirements for microbial enzymes involved in the production and consumption of methane and nitrous oxide. Frontiers in Microbiology, 3(FEB):1-20, 2012. doi: 10.3389/fmicb.2012.00061.

[17] Babett Wintsche, Karin Glaser, Heike Sträuber, Florian Centler, Jan Liebetrau, Hauke Harms, and Sabine Kleinsteuber. Trace elements induce predominance among methanogenic activity in anaerobic digestion. Frontiers in Microbiology, 7(DEC):1-12, 2016. doi: 10.3389/fmicb.2016.02034.

[18] Rudolf K. Thauer, Anne Kristin Kaster, Meike Goenrich, Michael Schick, Takeshi Hiromoto, 
and Seigo Shima. Hydrogenases from methanogenic archaea, nickel, a novel cofactor, and H2 storage. Annual Review of Biochemistry, 79(April):507-536, 2010. doi: 10.1146/annurev.biochem.030508.152103.

[19] Adrian Tersteegen and Reiner Hedderich. Methanobacterium thermoautotrophicum encodes two multisubunit membrane- bound $[\mathrm{NiFe}]$ hydrogenases. Transcription of the operons and sequence analysis of the deduced proteins. European Journal of Biochemistry, 264(3):930-943, 1999. doi: 10.1046/j.1432-1327.1999.00692.x.

[20] Judith A Fox, David J Livingston, William H Orme-Johnson, and Christopher T Walsh. 8-Hydroxy-5-deazaflavin-reducing hydrogenase from Methanobacterium thermoautotrophicum: 1. Purification and characterization. Biochemistry, 26(14):4219-4227, jul 1987. doi: 10.1021/bi00388a007.

[21] B. Demirel and P. Scherer. Trace element requirements of agricultural biogas digesters during biological conversion of renewable biomass to methane. Biomass and Bioenergy, 35(3):992-998, 2011. doi: 10.1016/j.biombioe.2010.12.022.

[22] Lei Zhang, Wenxiang Ouyang, and Aimin Lia. Essential Role of Trace Elements in Continuous Anaerobic Digestion of Food Waste. Procedia Environmental Sciences, 16:102-111, 2012. doi: 10.1016/j.proenv.2012.10.014.

[23] Jo De Vrieze, Lars De Lathouwer, Willy Verstraete, and Nico Boon. High-rate iron-rich activated sludge as stabilizing agent for the anaerobic digestion of kitchen waste. Water Research, 47(11): 3732-3741, 2013. doi: 10.1016/j.watres.2013.04.020.

[24] Muhammad Tahir Ashraf, Mads Ujarak Sieborg, Lars Yde, Chaeyoung Rhee, Seung Gu Shin, and Jin Mi Triolo. Biomethanation in a thermophilic biotrickling filter $-\mathrm{pH}$ control and lessons from long-term operation. Bioresource Technology Reports, 11:100525, 2020. doi: 10.1016/j.biteb.2020.100525.

[25] Brian Dahl Jønson, Mads Ujarak Sieborg, Muhammad Tahir Ashraf, Lars Yde, Juhee Shin, Seung Gu Shin, and Jin Mi Triolo. Direct inoculation of a biotrickling filter for hydrogenotrophic methanogenesis. Bioresource Technology, 318, 2020. doi: 10.1016/j.biortech.2020.124098.

[26] W. B. Whitman, E. Ankwanda, and R. S. Wolfe. Nutrition and carbon metabolism of Methanococcus voltae. Journal of Bacteriology, 149(3):852-863, 1982. doi: 10.1128/jb.149.3.852-863.1982. 